\title{
Development of Latent Finger Prints on Human Skin: A Review
}

\author{
Surender Pratap Singh \\ Former Dy. Supdt. (Finger Print) / Finger Print Expert \\ Central Finger Print Bureau, National Crime Records Bureau Govt. of India, Ministry of Home Affairs, \\ Mahipalpur New Delhi-110037, India
}

\begin{abstract}
There are still many areas in finger print science, which need further research to make this unique science of individualization more effective in crime investigation, development of latents on human skin is one such area. In case of homicide by strangulation, if decipherable latents could be developed and lifted from the skin, it would be another milestone in the history of fingerprints in criminal investigation. In cases of homicide by strangulation, crucial latent finger mark linking the perpetrator of the crime may be present on victims' skin, but attempts to retrieve such an evidence have not met with much success. Difficulty in developing fingerprints on skin is due to its function of regulating body's temperature, excretion of waste matter, and other bodily bio-chemical functions, both in live persons and the deceased. Moist surface of a living person's skin may lead to water soluble contents of the latents get washed away or the composition altered, but in case of human cadaver, theoretically, the possibility of finding such an evidence seems a little better. But there are many hurdles which the physiological processes happening inside a living human body or a cadaver may pose in recovering latents from skin surface. Furthermore, the skin of homicide victims may also be subjected to many severe circumstances, such as defacement, presence of saliva, blood, urine, other bodily fluids, ambient weather, postmortem changes, and putrefaction of body. Moreover, like in any other crime scene scenario, during investigation number of individuals handle a dead body, which may cause irreparable damage to the quality of existing finger print evidence, or possibly add new ones to the corpse's skin. The objective of this paper is to apprise the stakeholders with methods used in different countries for recovery of fingerprints from human skin, and their level of success.
\end{abstract}

Key Words:- Latent fingerprint, Cadaver skin, Strangulation, Cyanoacrylate fuming, fluorescent finger print powders, Iodine/Silver Transfer Method

\section{INTRODUCTION}

Developing latents finger prints on human skin may sound simple to one and all even some of our own fraternity members, particularly those with no or very little knowledge of human physiology, structure of skin, excretory system or chemical compositions of bodily fluids. Even a little success in the filed should be considered as a big achievement, as there are many hurdles, which the bio-chemical processes happening inside a living human body or a cadaver, may pose in recovering latents from skin surface.

A. Beginning of experiments for development of latents on human skin (1960s)

Finger print scientists started testing different available development techniques in the mid 1960's through the 1970's, for visualizing latent prints on human skin [1]. They tried using optical techniques, photography, iodine /silver plate transfer method, various powders including fluorescents with ALS, cyanoacrylate fuming, blood print enhancement chemicals, perhaps every technique available in those days, and achieved marginal successes in their efforts. Della Wilkinson in 2011, had reported in her study that majority of the human skin trials reportedly used, both live subjects as well as previously refrigerated corpses, whereas five studies published results from only living skin. Several recent papers have described the recovery of fingerprints deposited onto previously refrigerated bodies. Only three laboratory trials reported the recovery of fingerprints deposited onto unrefrigerated (some cases skin surface temperature was of a living individual) and unwashed human skin [2].

\section{B. Earliest Success in recovering fingerprints from} cadaver skin (1970s-1980s)

Persistence on the part of a few (fingerprint professionals) bore fruits in the mid-1970s. The Miami-Dade Police Department in Miami, Florida, had positive results in five cases involving physical assault or homicide. One of them in 1978 produced the first known identification of prints from human skin that resulted in a first-degree murder conviction [3]. In one of the articles in J. Forensic. Ident., published in 2005, it was shared that Japan and Canada also followed Miami, Florida, USA with successful cases in 1981 \&1982, giving references of Imamura, and Haslett [4]- [5].

\section{Experiments in Knoxville, Tennessee Police Department (1990s)}

In the year 1991, Knoxville, Tennessee Police Department got involved in a research project collaborating with University of Tennessee Hospital, and the Department of Anthropology at the University of Tennessee, USA and the FBI, to develop consistent and reliable technique to develop latent prints on skin, they decided to use only un-embalmed cadavers and to place latent prints composed of only natural perspiration and sebaceous material [6]. The researchers first examined the body of a 62-year-old white female who had been dead for 9 days. Areas of skin were sectioned into numbered squares drawn on the body. One researcher placed latent prints on the skin by wiping his hand across his brow or through his hair and then touching the cadaver. Most of these methods developed the latent prints up to approximately 1 hour after the prints had been deposited. For additional documentation, during the next several days, 
researchers tested the techniques on other cadavers, but most methods failed to provide consistent results [7].

\section{Further progress in the $21^{\text {st }}$ Century}

Experiments by Collective of four European Countries (published in 2010): In 2000, the Crime Scene Unit at the German Federal Criminal Police (Bundeskriminalamt) began a series of trials supported by various Federal Police Offices and Institutes of Forensic Medicine aimed at detecting and recovering latent fingerprints on the skin of corpses by using adhesive [8].

A collective of four European nations Germany, Austria, UK, and Denmark participated in the trials in accordance with Helsinki Declaration of 1983, for ethical standards on human experimentation. The four participating groups/countries placed 250 latents on 10 corpses each, in their respective countries (total 40 cadavers in 04 countries, 18 males, and 22 females, age between 15 to 98 ), leading to availability of 1000 prints for analysis. They used magnetic and plain black fingerprint powders, and for lifting Isomark $\mathrm{R}$, and gelatine foil was used.

The project "Latent Fingerprints and DNA on Human Skin" was the first systematic research in Europe dealing with detection of fingerprints and DNA left by offenders on the skin of corpses. Fingerprints were deposited by natural donors on corpses. The latent fingerprints were treated with magnetic powder or black fingerprint powder. Afterward, they were lifted with silicone casting material (Isomark $\circledR$ ) or gelatin foil. All lifts were swabbed to recover DNA. It was possible to visualize comparable and identifiable fingerprints on the skin of corpses (16\%). In the same categories, magnetic powder $(18.4 \%)$ yielded better results than black fingerprint powder $(13.6 \%)$. The number of comparable and identifiable fingerprints decreased on the lifts $(12.7 \%)$. Isomark $®(14.9 \%)$ was the better lifting material in comparison with gelatine foil $(10.1 \%)$ [9].

Table-1: Result of experiment with the type of powder and lift used

\begin{tabular}{|l|l|l|}
\hline S. No. & Experiment/Result & In Percent \\
\hline 1 & Recovery of Comparable and Identifiable prints on corpses & 16.0 \\
\hline 2 & With Black Magnetic Powder & 18.4 \\
\hline 3 & With Black Magnetic Powder & 13.6 \\
\hline 4 & Comparable and Identifiable prints with gelatin foil & 12.7 \\
\hline 5 & Recovery of Comparable and Identifiable prints with Isomark® & 14.9 \\
\hline
\end{tabular}

Certainly, it was a step forward in helping standardization of methods/techniques for recovery of latents from human cadaver. The experiments were done on 40 corpses (which is quite a good number) but using magnetic \& non-magnetic black finger print powder, and two types of lifting mediums. No other techniques like iodine, cyanoacrylate fuming, ALS, and RUVIS were used, which was like missing a golden opportunity to try different techniques and compare the quality of recovered latents, as it is not always easy to find such a good number of cadavers for finger print research. Moreover, only four countries of Europe participated, they could have included either more countries of the European Union, or countries representing other continents of the world, for better analysis. The results may or may not be similar in term of efficacy in other parts of the world with different skin types and local conditions. With a little more effort in finding collaborates from all continents of the globe, the unique endeavor could have become a Panworld project, with vaster analysis of developed latents. Nevertheless, every step placed forward, brings us closer to our goal.

\section{MATERIALS AND METHODS}

Material on the topic of recovery of latent finger prints on skin through books, published articles, research papers, PPTs, news, international journals, bulletins, academic platforms on Internet, conferences, workshops, discussions with finger print fraternity in India, formed the source of information to be reviewed.

The relevant material was sequenced in ascending order (i.e. earlier to later), to analyze the type work done, and the level of success achieved in recovery or development of fingerprints on skin, starting from the 1960s, until the work done in the $21^{\text {st }}$ century. The author himself holds post graduate qualification in Bio-science, and is also an accredited finger print expert (since 2001), thus he could use his knowledge, and two decades of professional experience in the field of fingerprint science to examine and identify the problem areas. There are social, cultural, ethical, and biological issues which have been posing difficulties in refinement of the previously used methods or to apply recent technological advancement for developing a Standard Operating Procedure (SOP) which could be used by the fraternity for detection, development and preserving of latents recovered from human skin.

\section{OBJECTIVE}

To review the bio-chemical, societal other technical challenges in the recovery of latent finger prints from human skin.

To apprise the stake holders with the various techniques used for development of latents on human skin, which may guide in further refinement of existing methods.

\section{DISCUSSION}

Unlike other substrates which investigators come across at the scene of crime, skin is a part of living human system, and it is also considered as the largest organ of the integumentary system. Here the cells are shed and are replaced by the new ones recurrently. It has pores which facilitate to keep the surface of skin moist, which in turn acts like a thin layered barrier for pathogens. Moreover, the process of sweating facilitates in regulating body temperature. The surface area of skin might expand or shrink, with extreme changes in ambient temperature. There can be many issues or problems a finger print expert might come across in detecting and developing latents on skin, be it the skin of a live person or a cadaver. 


\section{A. Secretions of sudoriferous (sweat) glands and} their impact on recovery of latents

Three primary glands contribute to the production of sweat. These are the sudoriferous glands (eccrine and apocrine) and the sebaceous glands. Each gland contributes a unique mixture of chemical compounds, which either exude from pores onto the friction ridges or are transferred to the friction ridges through touching an area (e.g., the forehead, underarm, etc.). Several million of eccrine glands are distributed throughout the body, most commonly on the palms of the hands and soles of the feet, and least numerous on the neck and back. The other sudoriferous gland present in skin is the apocrine glands, which are associated with the coarse hair of the armpits and pubic area. They are larger than eccrine glands and secrete a thicker fluid. Third type, the sebaceous glands are relatively small sac-like organs and can be found in the dermis layer of skin. They are found throughout the body and are associated with body hair. They are particularly abundant on the scalp, face, anus, nose, mouth, and external portions of the ear [10].

\section{B. Human body temperatures of the living and the dead}

Actual temperature at which the body is maintained varies between species, but this variation is not significant amongst the same species. In humans, normal oral temperature is 37 ${ }^{\circ} \mathrm{C}$ or $98.6^{\circ} \mathrm{F}$, which may be a little higher in young adults, that is up to $37.7^{\circ} \mathrm{C}$. Moreover, the temperature of different parts of the body also differ, the extremities are comparatively cooler than the rest of the body, while the temperature of scrotum is $32{ }^{\circ} \mathrm{C}$, that is 5 degrees less than the rest of the living human body.

The normal human core temperature undergoes a regular circadian fluctuation of 0.5 to $0.7^{\circ} \mathrm{C}$. In individuals who sleep at night and are awake during the day (even when hospitalized at bed rest), it is lowest at about 6.00AM and highest in the evening. In women there is additional, there is additional monthly cycle of temperature variation characterized by a rise in basal temperature at the time of ovulation [11].

\section{Rate of Cooling of dead bodies}

Dr. Burman Wilkie J., M.D., Edinburgh, Scotland, experimenting on dead bodies of nine persons suffering from different disease (each individual suffered from different/different set of diseases) observed, on eliminating the last two cases (out of nine), that the mean average rate of cooling in the seven others (all under fairly similar conditions as to external circumstances) was $13 / 5{ }^{\circ} \mathrm{F} / \mathrm{Hr}$., the minimum rate being $11 / 5{ }^{\circ} \mathrm{F} . / \mathrm{Hr}$. and the maximum 2 $1 / 5{ }^{\circ} \mathrm{F} / \mathrm{Hr}$., as is shown in detail in the following table (2). Dr. Burman published his finding in the $28^{\text {th }}$ British Medical Journal, more than a century ago in the year 1874 . Probably he was one of the pioneers, who made an elaborate and systematic study of post-mortem changes in the body temperatures [12].

Table-2: Average Rate of Cooling in ${ }^{\circ} \mathrm{F} / \mathrm{Hr}$.

\begin{tabular}{|c|c|c|c|c|c|}
\hline Case No. & $\begin{array}{l}\text { Hours under } \\
\text { Observation }\end{array}$ & $\begin{array}{l}\text { Temperature at Time } \\
\text { of Death } \\
\left(\text { in }{ }^{\circ} \mathrm{F}\right)\end{array}$ & $\begin{array}{l}\text { Temperature at Time } \\
\text { of Cessation of } \\
\text { Observations } \\
\left(\text { in }^{\circ} \mathrm{F}\right)\end{array}$ & $\begin{array}{l}\text { Degrees } \\
\text { Cooled } \\
\text { (Degree } \\
\text { Fahr.) } \\
\end{array}$ & $\begin{array}{l}\text { Average Rate of } \\
\text { Cooling per Hour } \\
\left(\text { in }{ }^{\circ} \mathrm{F}\right)\end{array}$ \\
\hline 1 & 25 & $1014 / 5$ & $732 / 5$ & $282 / 5$ & $11 / 5$ \\
\hline 2 & 12 & $1092 / 5$ & $823 / 5$ & $264 / 5$ & $21 / 5$ \\
\hline 3 & 11 & $\begin{array}{l}982 / 5^{*} \\
\text { ('Presumedly.) }\end{array}$ & 82 & $162 / 5$ & $13 / 5$ \\
\hline 4 & 03 & $1052 / 5$ & $1002 / 5$ & 5 & $13 / 5$ \\
\hline 5 & 16 & 101 & $804 / 5$ & $201 / 5$ & $12 / 5$ \\
\hline 6 & 12 & $1004 / 5$ & 83 & $174 / 5$ & $12 / 5$ \\
\hline 7 & 12 & $1081 / 5$ & 86 & $221 / 5$ & $14 / 5$ \\
\hline Average and Mean & 13 & $1033 / 5$ & 84 & $193 / 5$ & $13 / 5$ \\
\hline
\end{tabular}

After death, the body temperature stays relatively constant; this is referred to as the 'postmortem temperature plateau.' In moderate to cool climates, this temperature plateau lasts for 1-3 $\mathrm{h}$, and this is then followed by a linear rate of cooling (between 0.5 and $1.5^{\circ} \mathrm{C}$ per hour) for the next $10-16 \mathrm{~h}$. Then, as the body temperature approaches ambient temperature, the hourly cooling rate slows down. Estimating the time since death based only on body (rectal) temperature is often inaccurate since the length of the temperature plateau is generally unknown, and such an assessment is useless when the body temperature has approached the ambient temperature [13]-[14].

The technique applied for recovery of latents can have varied results in terms of quality of latents recovered from the skin of living persons as well as of cadavers, because of temperature variations.

\section{Skin of live person, as substrate for developing latents}

Latents finger prints are transferred to a substrate or a surface due to the presence of sweat on the friction ridges. Human sweat is a composition of salts, lipids, urea, water etc., which when comes into the contact with a surface leaves an image of friction ridges. On application of appropriate powders, chemicals or fumes, these hidden designs become patent.

Skin possesses a number of unique qualities that distinguish it from other specimens examined for latent prints. Skin tissue grows and constantly renews itself, shedding old cells that might contain the imprint of an assailant's grip. Its pliability allows movement and, hence, possible distortion of fingerprints. As the skin regulates the body's temperature 
and excretes waste matter through perspiration, latent prints can be washed away [15].

\section{1) Changes in sebum composition with the age of the donor}

The free fatty acid composition in sebum changes dramatically with age of the donor. The approximate percentage of fatty acids in newborns (approximately 5 days old) has been reported to be only about $1.5 \%$ of the overall sebum composition. This value rises dramatically to about $20-23 \%$ in young children (age 1 month to 4 years). The value then stabilizes to $16-19 \%$ for adolescent and post adolescent subjects (up to approximately 45 years of age) [16]-[17].

\section{latents}

\section{E. Skin of cadaver, as substrate for developing}

1) Social, cultural, religious and ethical issues: Development of latents on the skin of a human body, may come across a number of cultural, social and religious barriers. Probably in most parts of the world, and in most religions, a dead body is considered sacrosanct, the family members and relatives would not allow any unauthorized handling or do anything which may distort the look of the body in any little way whatsoever. In India, during post death Hindu rituals, a dead body is bathed with water from a sacred river, or fresh water purified with few drops of water such holy river. Similarly, there are many other similar processes which are practiced to save the sanctity of human remains, from getting contaminated. Once the journey for cremation starts, the body is not kept on the ground, street or road, only after reaching cremation ground it is placed on a designated area. Although, with the passage of time, people have also started adapting to the changes, now there are funeral vans for the last journey, LPG/PNG or electricity aided furnaces, replacing wood pyres for faster and pollution free cremation.

2) Biological / chemical and other technical issues: Biologically the skin of a dead person, is rather a better substrate for development of latents, than that of a living person. There are many changes that start taking place after a person is death, i.e. change in the body temperature (cooling down of body), rigor mortis, and putrefaction. The surrounding conditions like age, body type, sunlight, temperature, humidity etc. also play role in accelerating or hindering the speed of post mortem vicissitudes (including putrefaction)

One of the externally visible signs of autolysis (post mortem auto-destruction) is skin slippage. During autolysis, the junction of the epidermis and dermis is weakened by the release of hydrolytic enzymes [18]. In case putrefied bodies, fingerprint experts might not find it convenient to use powders for the recovery of latents. They can try using touch-less techniques like Alternative Light Source, UV, fumigation, photography etc. accordingly, although the possibilities for recovery of latents may not be exuberant.

3) Fresh and Frozen cadavers: Tissue plasticity was preserved in fresh (not frozen) cadavers for 12 days. Venous bleeding was also conserved, which seems to be one of the main benefits compared to chemically conserved anatomical or frozen cadaveric models [19]. Against the general belief that latents can be easily recovered from the skin immediately post death, perhaps it will be easier after a couple of hours post mortem, once the process of perspiration has stopped and moisture evaporated, or the contents of sweat settled as a thin \& drier (comparatively) layer. Ambient air, temperature, humidity will play a critical role in recovery of latents, apart from different areas or parts, and natural post mortem cooling rates of human body. The results of developing latents also vary on fresh or frozen dead bodies.

\section{F. Medico-legal Implication}

There could also be some medio-legal issues, which might pose hinderance in the recovery of latents from human skin. In India, when death takes place in abnormal circumstances, the police would send the body for post mortem to a government hospital, and it is done immediately after initial investigation, crime scene photography etc. by the police and forensic teams. If an expert would apply fingerprint powder, chemicals, or expose the body to fuming, it may cause discoloration of the areas where processing had been done. In such a scenario, there will be both legal and other technical pertaining to postmortem; the coroner/ physician might refuse to accept the body for post mortem examination, which had already been processed upon by fingerprint personnel. The coroner/physician might find it difficult to note down visible physical observations (marks etc.), got concealed due to application of powders of fuming of chemical substances. Moreover, Police / prosecution too may find it difficult to answer questions pertaining to handling the body, which might be posed by the defense/court during trial.

\section{TECHNIQUES USED THEIR EFFICACY}

Techniques used for development of latents on human skin

The fingerprint scientists have used a variety of methods for the recovery of latents from the skin of animals and humans, since the 1960's. I have tried to give details of number of such method used by finger print experts/researchers in different parts if the world, for their experiments on human skin.

\section{A. Dusting with Magnetic powder}

Dusting the substrate with finger powder leads physical adherence of the particles with the residual material transferred through the pores present on the friction ridge skin. Application of powders is recommended for smooth non-porous surfaces, with soft brushes. Magnetic powders used with magna brush or magnetic wand, are supposed to be more efficient, than animal hair or fur brushes. The magna brush may not be used for metal surfaces, as some metals may attract the magnet present in the head of the applicator, and damage the prints of the friction ridges. FBI, in an article published in Law Enforcement Bulletin in 1996 has recommended for the use of regular magnetic powder, post-superglue fuming, for the recovery of latents finger prints from human skin.

\section{B. X-ray Techniques}

X-ray Techniques used in fingerprint work essentially employ powder techniques, as finely powdered lead, 200 to 400-mesh, is used to develop the latent prints, and X-rays 
then used to visually record the latent print image. X-rays are electromagnetic radiations of extremely short wavelength, extending from the extreme ultraviolet into the gamma ray region of the spectrum. At low voltages, $5 \mathrm{kV}$ to $35 \mathrm{kV}$, x-rays have low energy and little penetrating power, and are referred as Soft X-rays. X-rays produced by medium voltages, $35 \mathrm{kV}$ to $150 \mathrm{kV}$, are used for medical diagnostic purposes. At higher voltage, $150 \mathrm{kV}$ to $500 \mathrm{kV}$, X-rays possess greater energy and have more penetrative power. $\mathrm{X}$ rays produced at these higher voltages are referred to as Hard $\mathrm{X}$-rays [20]. The technique did not get popular, due to number of reasons, like the cost involved, importability of the equipment to the scene of crime, extreme health hazard, highly technical nature of the system. Perhaps was never found suitable as the primary method for latent finger recovery, from common surfaces or specific substrates like skin.

C. Direct Transfer Method: Kromekote card lifting (for recovery of latents from skin)

A latent fingerprint on human skin may be lifted prior to developing by firmly pressing the Kromekote card, an 80pound high gloss paper to the surface for 2 to 3 seconds. Lifting of the card should be done carefully to prevent slippage, and should be completed with a continuous motion until entirely free of the skin surface. Then the Kromekote card is processed with black fingerprint powder using fiberglass brush, to develop the latent impression. The print will be a mirror image of the actual fingerprint, and it should be photographed and reversed to avoid confusion. Irregularities in the skin surface may require the use of silicone rubber casts to lift the developed print. The kromekard technique is capable of lifting prints from living victims for up to $11 / 2$ hours after the print was placed. Cosmetic oil and lotions seriously affect the retention of latent fingerprint impressions. On deceased victims, the fingerprint examination should be done before the body is refrigerated. The undersides of the biceps, sides of the torso, the neck, and the tops of the feet most successfully yield latent impressions. The Kromekote lift technique may be repeated several times on the same impression without apparent damage to the print. Stretching of elastic skin will provide best results. In cases where the skin surface has been immersed in water, air drying may permit the lifting of sebaceous prints even for immersion periods of more than 30 minutes [21]. The technique was tried by Forensic Identification Unit (FIU), Vancouver Police Department in 2005 , to recover latents from upper arms of homicide victim, but the technique failed to yield print activity.

\section{Electronography}

Electron radiography or Transmission Electronography is an electronographic technique wherein a lead foil is placed between the X-ray source and the object being examined. The radiations passing through the object and striking the film are the electrons emitted by the lead foil [22]-[23]. Olsen, Robert D. Sr., in his book, Scotts Fingerprint Mechanics, published in 1978, has found this technique to be of little practical application in fingerprint work.

\section{E. Iodine-silver plate transfer}

Iodine fuming is one of the oldest methods used for development of latents on human skin. The process involves, fuming the areas of victim's skin where there are chances of having latent prints of the suspect, with this help of iodine fuming apparatus. A sliver plate is placed on the developed ridge impression, which is examined under normal bright light [24]. Exposure of living persons to iodine fumes can cause skin irritation, excessive tears, breathlessness, headache, and can also become a reason of allergic reactions, needing immediate medical intervention.

\section{F. Laser detection by inherent luminescence}

Laser (light amplification by stimulated emission of radiation) and other Alternative Light Sources (ALSs) are often used to detect or locate latent fingerprints, and other physical evidence like fibers, blood, semen, saliva, and similar biological material. Certain chemical substances occurring naturally or as contaminants in the latent fingerprint residue fluoresce even without treatment with fluorescent dyes or powders. Laser detection of latents by inherent luminescence may not be a great success very often, but it is always better to try Laser and ALS before proceeding for powdering or chemical processing of a surface. Laser is extremely dangerous and can cause irreversible damage to the eyes, thus use of protective goggles and body suit is advisable for the operator.

Delmas, studied the use of luminescent magnetic powder in conjugation with cyanoacrylate fuming and laser examination of cadavers. Five cadavers were examined after intentionally placing latent prints on body surfaces, and identifiable latents were recovered from four surfaces [25][26].

\section{G. Ruthenium Tetroxide (RTX)}

A was study conducted by Trapecar M. et al, of Forensic Laboratory and Research Centre, Police, Ministry of the Interior, Slovenia, (published in Science \& Justice, 2007) to recover latents from human skin using four different fingerprint powders i.e. magnetic jet black, magnetic silver, silver special, Swedish black, and two other methods i.e. Cyanoacrylate Fuming (CA) \& Ruthenium Tetroxide (RTX). Having examined skin surfaces with a forensic light source, they observed that the fingerprint impressions remained visible up to fifteen (15) minutes after intentionally placing them on the skin surface of living subjects and dead bodies. Finger marks were recovered and positive results were achieved with Magnetic Black and Swedish Black powder on living subjects. On dead bodies finger marks treated with cyanoacrylate were visible, but those treated with RTX, Swedish Black and Magnetic JetBlack powder were useful for potential comparison. On dead bodies best results were obtained with RTX method [27].

\section{H. Cyanoacrylate with Rhodamine 6G (R6G)}

Members of Vancouver Police Department's Forensic Identification Unit published their report in Identification Canada in June 2005, on development of latents off human cadaver, using transfer of fingerprint matrix to photographic paper and cyanoacrylate fuming in conjugation with rhodamine staining. The team tried to develop latents from homicide victims' legs, and later on the upper arms (the actual surface exposed at the time of murder). After the body had been cooled for a number of hours in a crypt, test prints 
were applied to both ankles. The first technique failed to yield print activity. In the second technique they first developed latents with $\mathrm{CA}$ and then treated the developed prints with rhodamine 6G (R6G) in methanol carrier. Without rinsing, the area was examined under alternative light source at $505 \mathrm{~nm}$. Prints were photographed with lighting provided by the ALS. Level-III detail was visible in the test prints. Although the cyanoacrylate had settled on the upper arms after CA fuming, no fingerprint activity was observed [28].

\section{Europium aryl-beta-diketone Method}

Canadian Scientist Della Wilkinson, of Royal Canadian Mounted Police, Ottawa recovered 12-identifiable friction ridge skin impressions, 10 from buttocks and legs, one from the neck of a human cadaver. The application of europium luminescence to the visualization of cyanoacrylate developed fingerprints is reported. Extremely fluorescent europium chelates are produced by the reaction of Eu3+ ions with aryl-beta-diketones. Excitation of the organic ligand (ion or molecule attached to a metal atom) occurs at $350 \mathrm{~nm}$ for europium tris (thenoyltrifluoroacetone). (TEC) and europium narrow band $(10 \mathrm{~nm})$ emission is observed at 614 $\mathrm{nm}$ as a result of an intramolecular energy transfer. The europium aryl-beta-diketone complexes are transferred into the interior of the polymeric cyanoacrylate from an aqueous methyl ethyl ketone solution. A two-phase system is established with methyl ethyl ketone, water and chelate outside the polymer and methyl ethyl ketone and chelate inside. As the print dries the ketone evaporates 'locking' the chelate inside the cyanoacrylate. Sufficient TEC is deposited in the polymer so that the print is easily seen under 7 $\mathrm{mW} / \mathrm{cm} 2$ of $\mathrm{Hg}$ light. Washing away of background contamination does not harm the fluorescent print. Prints deposited on cadaver skin and fumed with cyanoacrylate have been detected with good detail by this method [29].

\section{FINGERPRINTS ON HUMAN SKIN: INDIAN SCENARIO}

Sufficient research has been conducted in Indian on other aspects of finger print science, like development of new powders, development of prints in difficult environmental conditions, poroscopy, edgeoscopy, history of finger print science in India, population \& gender studies based on finger print data, but the author could not come across any information on development of fingerprint on human skin, or for that matter on any other similar animal skin.

One of the major problems in India, for conducting research in the area of development of finger prints human skin for, is unavailability of cadavers itself. Here, donation of dead bodies for study is extremely limited. Moreover, most of the finger print bureaux (FPBx) in India are either part of the police or directly under their administration, and the police here (like any other highly populated country) is always overwhelmed with work. In the existing scenario, conducting primary research by police personnel, in the field of fingerprint science may not be possible. Furthermore, at the entry level of employment for police fingerprint set-up, science graduation is not a mandatory qualification, in all provinces/states of India. In undergraduate studies; there is not much of training given in conducting actual research, only at post graduate level students get proper exposure to the techniques of conducting research, and writing a thesis. So, the staff working in the finger print bureaux of India, may not be possessing comprehensive know how of carrying out a scientific research, though they are well trained in examination of scientific evidence. While in the Central or State Forensic Science Laboratories (finger print is usually not a part of FSLs) research is conducted by or under the guidance of scientists/officers who possess minimum post graduate qualifications in science (i.e. MSc). So, technically also police fingerprint staff is not be at par with forensic experts working in the Central and State Forensic Science Laboratories. Nevertheless, for the last two decades there has been an increase in the number of applicants and recruits with post graduate qualifications in science for employment in finger print bureaux of India. If we select $10-20 \%$ of these recruited science post graduates (purely on merit), and deploy them exclusively for primary research in finger prints, in collaboration with Universities, Medical colleges, and forensic science laboratories, then for sure, in coming one decade or so, we will be able to have a good number of forensic finger print researchers/scientists, and have better understanding of under explored areas of fingerprint science in our country.

The author who has worked with the nodal government finger print agency in India for two decades, is not in the known of any such experiment conduced to recover latents from skin surface whether of an animal or a human being (live or cadaver). He has also not come across any report from individuals or researchers from other Fingerprint Bureaux, Colleges, Universities or Forensic Science Departments in any part of India. Although, while holding the position of Sr. Scientific Officer (Finger Print) on deputation for one year, of the newly established Finger Print Unit, at the Delhi State Forensic Science Laboratory he himself was once asked by the acting head of the organization, whether he could try developing latents from the neck area of a homicide victim, who purportedly was killed by strangulation. But due to lack of even basic finger print powder, chemicals and equipment, the opportunity could not be availed. The author probably is the only finger print expert in India, who has worked for Government's Central Finger Print Bureau, Bureau of Police Research and Development, Central Detective Training School/Institute, and Forensic Science Laboratory.

\section{CONCLUSION}

In the present scenario with lack of indigenous research and literature based on actual experiments done for the recovery of latents from human skin in Indian conditions, the paper will certainly be of help in apprise or update our fraternity on the work done in the field in different parts of the world since the 1960s. It may motivate researchers from the field of forensic medicine, forensic science, forensic chemistry, fingerprint science etc. to get involved in the field, and find an indigenous and workable technique for development of latent finger impression, especially on skin of unidentified 
cadavers, at least to start with. Research in the field may also assist the law enforcement agencies in identifying culprits, when no other evidence is available at their disposal.

After going through available literature and analyzing the reports on different techniques used for recovery of latents, cyanoacrylate fuming in conjugation with certain dyes or magnetic powders seems to have been comparatively more successful in development of friction ridge impressions on the skin of cadavers. Although we cannot recommend any one method or technique for successful recovery of latents from all types of skin, as every human body is unique.

\section{REFERENCES}

[1] Sampson, William C. \& Sampson, Karen L. (2005), Recovery of latent prints from human skin, J. Forensic Identification, 55 (3), 362.

[2] Wilkinson, Della A. (2011), A review of fingerprints from human skin, Identification Canada, 34(2): 48-49.

[3] Mellis, A. (1981), The Spa Murders. Fingerprint Whorld, January, 55-57.

[4] Imamura, M., Asahida, M. (1991), Fingerprint Lifted from Cadaver Skin Surface, Ident. News, 41(2), 111.

[5] Haslett, M. Peel Regional Police Identification Bureau, Brampton, Ontario, Canada, through Sampson, William C. \& Sampson,

[6] Bohanan, Arthur M. (1993), Police Specialist, Knoxville Police Department et al, Observations and recommendations for developing latent prints on human skin, Document available on https://www.ncjrs.gov/pdffiles1/Digitization/146374NCJRS.pdf, Pg. 3-4.

[7] Futrell, Ivan Ross. (1996), Hidden Evidence: Latent on Human Skin, FBI Law Enforcement Bulletin, April 1996) Available at: http://www.iowaiai.org/hidden-evidence-latent-prints-on-humanskin/ Accessed: 26.05.2020

[8] Lenertz O, Schçnborn S, Bohnert M. (2002), Daktyloskopische Spuren auf menschlicher Haut-Ergebnisse einer praxisorientierten Versuchsreihe. Arch Kriminol 2002; 210:129-36.

[9] Doris, Farber., Andrea Seul., Hans-Joachim, Weisser., and Michael Bohnert., (2010), Recovery of Latent Fingerprints and DNA on Human Skin, J. Forensic Sci, 2010 doi: 10.1111/j.1556-4029.2010. 01476.x Available at: interscience.wiley.com Accessed: 06.05.2020.

[10] Anderson, K. N., Anderson, L. E., Glanze, W. D., (1998), Eds. Mosby's Medical, Nursing, and Allied Health Dictionary, 5th ed.; Mosby, Inc.: St. Louis, MO, 1998, pg.1561.

[11] Ganong, William F., (1997), Central Regulation of Visceral Function, Review of Medical Physiology, Appleton \& Lange, A Simon \& Schuster Company, Stamford, Connecticut, USA, $18^{\text {th }}$ Edition, Chapter-14, Pg. 235.

[12] Burman, J. Wilkie. (1874), Rate of Cooling of the Human Body after Death, British Medical Journal, 28th, 1874, pg. 1000. Available

https://www.ncbi.nlm.nih.gov/pmc/articles/PMC5327323/pdf/edin bmedj74080-0034.pdf Accessed: 17.05.2020.

[13] Nokes, Leonard Derek Martin, Henssge, C., Knight, B. H., Madea, B. and Krompecher, T., (2002), The estimation of the time since death in the early post-mortem period (2nd Edition). London: Hodder Arnold Publication.

[14] M. Tsokos, R.W. Byard, Postmortem Changes: Overview, Encyclopedia of Forensic and Legal Medicine (Second Edition), $2016 \quad$ Available at: https://www.sciencedirect.com/topics/medicine-anddentistry/algor-mortis Accessed: 26.05.2020.

[15] Futrell, Ivan Ross. (1996), Hidden evidence: latent prints on human skin, FBI Law Enforcement Bulletin, April 1996.

[16] Ramasastry P, Downing DT, Pochi PE, et al. Chemical composition of human skin lipids from birth to puberty. J Invest Dermatol 1970; 54:139-144.
[17] Brian Yamashita and Mike French, Latent print Development, Fingerprint Source Book (2014), Ch-7, pg 7-8. Available at: https://www.crime-sceneinvestigator.net/fingerprintsourcebkchp7.pdf.

Accessed 225.06.2020.

[18] M.K. Marks, M.A. Tersigni-Tarrant, (2016), Death Investigation Systems: Decomposition, Patterns, and Rates in Encyclopedia of Forensic and Legal Medicine (Second Edition), 2016 Available at: https://www.sciencedirect.com/topics/medicine-anddentistry/algor-mortis Accessed 26.05.2020.

[19] Csókay András, Attila Josvai, Csókay Gergely, Jäckel Márta, 2019, The Importance of daily fast fresh cadaver dissection (How can we organize it?), Journal of Neurology \& Stroke, January 9 , 2019, Vol 9 issue 1, Hungarian Defence Forces Medical Center, Available at: https://medcraveonline.com/JNSK/the-importanceof-daily-fast-fresh-cadaver-dissection-how-can-we-organizeit.html, Accessed: 17.05.2020.

[20] Olsen, Sr. Robert D., (1978), X-Ray Techniques, Latent Fingerprint Electronic Techniques Scott's Fingerprint Mechanics; Charles C Thomas: Springfield, IL, USA, Chapter VIII (105) 344.

[21] G J Reichardt; J C Carr; E G Stone., (1978), Conventional method for lifting latent fingerprints from human skin surfaces, Journal of Forensic Sciences, 1978, V 23, N 1, P 135-141. Available at: https://www.ncjrs.gov/App/publications/Abstract.aspx ?id=45942 Accessed: 26.05.2020.

[22] Kodak: Photography in Modern Industry. Eastman Kodak Co. Rochester, NY, 1969

[23] Graham, Daniel: The use of X-Ray Techniques, in Forensic Investigations. London, Churchill Livingstone, 1973.

[24] L.J. Casarett, L.J., and Doull, J. (Editors) (1975), Toxicology of the Respiratory System, Toxicology: The Basic Science of Poisons, Macmillan, New York, 1975, pg. 201-224.

[25] Lee, Henry C., and Gaensslen R.E., (2001) Advances in finger Print Identification, $2^{\text {nd }}$ Edition, 2001, Ch. 4, pg. 149.

[26] Delmas, B.J., Postmortem latent print recovery from skin surfaces. J. Forensic Ident., 38, 49, 1988

[27] Trapecar M, Balazic J., (2007) Fingerprint recovery from human skin surfaces, Science \& Justice. 2007 Nov; 47(3):136-40. Available on: https://pubmed.ncbi.nlm.nih.gov/18051035/ Accessed: 03.06.2020.

[28] Colonval, Dave \& Wendell Joanne, (2005) Finger Tips: Fingerprin Experiments on a Homicide Victim, Identification Canada. June 2007; 28(2): 26-28.

[29] Della A. Wilkinson, Europium aryl-diketone complexes as fluorescent dyes for the detection of cyanoacrylate developed fingerprints on human skin, Journal of Forensic Identification Volume:43 Issue:2 Dated:(March- April 1993) Pages: $154-165$ 